diarrhoea, and fever (Van Reen, 1966). Vomiting and fever occurred on each occasion that the patient was dialysed against fluid diluted with rain water stored in a galvanized iron tank and correlated with a high concentration of zinc in both tank-water and plasma. Additionally she became severely anaemic at a time when she had a grossly raised red cell zinc concentration. The occurrence of toxic symptoms during her first home dialysis implies acute zinc poisoning, and their recurrence with each subsequent dialysis the possibility of acute-on-chronic toxicity.

Gastrointestinal disturbances and haemolysis are symptoms of copper poisoning in haemodialysis (Blomfield et al., 1971), but measurements in this patient disclosed no undue contamination of the dialysis fluid by copper, nor excessive uptake by plasma or red cells. The small increase of plasma free copper may have been due to displacement by zinc of liver copper which had accumulated during previous hospital dialyses and which, in this anephric patient, could not be cleared from the blood by the renal route.

Previous studies of zinc uptake in haemodialysis patients have all shown small rises in arterial plasma zinc concentrations during dialysis, despite dialysis fluid zinc concentrations lower than the plasma levels (Maher et al., 1965; Blomfield et al., 1969; Mansouri et al., 1970; Mahler et al., 1971; Zazgornik et al., 1971), and high predialysis plasma zinc has been found in some patients (Mansouri et al., 1970; Zazgornik et al., 1971), suggesting zinc accumulation.

The experimentally dialysed dogs in this study showed avid plasma binding of zinc to levels many times greater than in the dialysis solution, with a resultant progressive rise in arterial plasma zinc and a possible increase in liver zinc concentrations. Simultaneous copper uptake studies in these dogs have been reported previously (Blomfield et al., 1971). A comparison between zinc and copper uptake from similar bath fluid concentrations shows a relatively greater increase of zinc in plasma returning from the dialysis coil and in arterial plasma but a comparatively lower liver uptake of zinc at the end of the twohour dialysis period.

Although the major excretory route of zinc is in pancreatic juice, zinc accumulates initially in the liver, a fact which has led to the use of the radioisotope ${ }^{\circ} \mathrm{Zn}$ as a liver scanning agent
(Johnston et al., 1967). Intravenous injection of this radioisotope in man has shown a five-minute half-life in the circulation and a prompt removal and concentration by the liver (Johnston et al., 1967).

These studies emphasize the dangers of metal poisoning in haemodialysis. The large volumes of water used for haemodialysis and the binding of metals by plasma proteins can lead to acute or cumulative toxicity from water with metal concentrations which are within acceptable limits for drinking purposes.

The haemodialysis coils used in the experimental dialysis of dogs were supplied by Travenol Laboratories Pty., Rosebery, N.S.W. We would like to thank Dr. J. H. Stewart, Dr. D. C. Cattran, and Dr. J. A. Charlesworth, of Sydney Hospital, Sydney, Miss K. L. Warton, of Royal Alexandra Hospital for Children, Sydney, and Dr. D. A. McCredie, of the Royal Children's Hospital, Melbourne, for their contributions to these studies.

Requests for reprints should be addressed to E.D.M.G., Medical Research Department, Sydney Hospital, Sydney, N.S.W. 2000, Australia.

\section{References}

Blomfield, J., McPherson, J., and George, C. R. P. (1969). British Medical Fournal, 2, 141.

Blomfield, J., Dixon, S. R., and McCredie, D. A. (1971). Archives of Internal Medicine, 128, 555

Johnston, G. S., Hupf, H. B., Gotshall, E., and Kyle, R. W. (1967). American fournal of Roentgenology, Radium Therapy and Nuclear Medicine, 101, 548.

Maher, J. F., Freeman, R. B., Setter, J. G., Rubin, M., and Schreiner, G. E. (1964). Transactions of the American Society for Artificial Internal Organs, 10, 332.

Maher, J. F., Freeman, R. B., Schmitt, G., and Schreiner, G. E. (1965) Transactions of the American Society for Artificial Internal Organs, 11, 104.

Mahler, D. J., Walsh, J. R., and Haynie, G. D. (1971). American fournal of Clinical Pathology, 56, 17.

Mansouri, K., Halsted, J. A., and Gombos, E. A. (1970). Archives of Internal Medicine, 125, 88.

Manzler, A. D., and Schreiner, A. W. (1970). Annals of Internal Medicine, 73, 409.

Matter, B. J., Pederson, J., Psimenos, G., and Linderman, R. D. (1969). Transactions of the American Society for Artificial Internal Organs, 15, 309.

Van Reen, R. (1966). Zinc Metabolism, ed. A. S. Prasad, p. 411. Springfield, Illinois, Thomas.

Zazgornik, J., Kotzaurek, R., and Schmidt, P. (1971). Klinische Wochenschrift, 49, 278.

\title{
Plasma Steroid and Luteinizing Hormone Levels during Prostaglandin F2 $\alpha$ Administration in Luteal Phase of Menstrual Cycle
}

\section{KEITH HILLIER, ANGELA DUTTON, C. S. CORKER, ALBERT SINGER， M. P. EMBREY}

British Medical fournal, 1972, 4, 333-336

\section{Summary}

An intravenous infusion of prostaglandin $F_{2} \alpha$ (12.5$250 \mathrm{\mu g} / \mathrm{min}$ ) was administered in four volunteers in the mid-late luteal phase and three in the early luteal phase of the menstrual cycle.

Frequent measurement of plasma progesterone, oestrogens, and luteinizing hormone( LH) showed that adminis-

Nuffield Department of Obstetrics and Gynaecology, University of Oxford, The John Radclife Hospital, Headington, Oxford

KEITH HILLIER, B.SC., PH.D., Research Fellow

ALBERT SINGER, M.B., M.R.C.O.G., Senior Registrar

M. P. EMBREY, M.D., F.R.C.O.G., First Assistant

M.R.C. Neuroendocrinology Unit, Department of Human Anatomy, South Parks Road, Oxford

ANGELA DUTTON, M.I.BIOL., Research Assistant

C. S. CORKER, B.SC., D.PHIL., Research Worker tration of high doses depressed plasma progesterone levels in the late luteal phase and caused concomitant side effects. Levels of progesterone in the early luteal phase were unafiected. In both phases oestrogen and LH levels were little altered. In two subjects, hourly progesterone levels measured throughout the day at a similar time in a subsequent control menstrual cycle showed an appreciable variation in one but steady levels in the second. This variation may contribute to the magnitude of the fall in progesterone noted during the infusion of prostaglandins.

\section{Introduction}

Experimental evidence indicating that the prostaglandins possess luteolytic activity has suggested the possibility of a novel approach to fertility control. Prostaglandin $\mathrm{F}_{2} \alpha\left(\mathrm{PGF}_{2} \alpha\right)$ acts as a luteolysin in many non-primate laboratory animals (Blatchley 
and Donovan, 1969; Pharriss and Wyngarden, 1969; McCracken, Glew, and Scaramuzzi, 1970).

Limited investigations of its effect on subhuman primate corpora lutea indicate that prostaglandins are not luteolytic in the early luteal and mid-luteal phases (Kirton, Pharriss, and Forbes, 1970; Kirton 1972).

Attempts to induce menstruation in patients by administering prostaglandins have given results that cannot be interpreted unequivocally. Although Karim (1971) reported that prostaglandin can induce menstruation other workers could generally show no decrease in progesterone in ovulating women infused with $\mathrm{PGF}_{2} \alpha$ (Wiqvist, Bygdeman, and Kirton, 1970; LeMaire and Shapiro, 1972) or prostaglandin $\mathrm{E}_{2}\left(\mathrm{PGE}_{2}\right)$ (Henzl, Ortega, Cortes-Gallegos, Tomlinson, and Segre, 1972).

Lehmann, Peters, Breckwoldt, and Bettendorf (1972) showed that in one case a four-hour infusion of $\mathrm{PGF}_{2} \alpha$ in an average dose of about $100 \mu \mathrm{g} / \mathrm{min}$ on day 21 of a 28 -day cycle significantly depressed progesterone levels in the 72 hours after infusion. It appears that dosage, route of administration, and temporal factors may play an important part in eliciting a response, and may partly explain the variation in results. Certainly a paucity of evidence exists at this time to substantiate the suggestion that prostaglandin depress progesterone synthesis in the human corpus luteum. An investigation using intravenous administration of $\mathrm{PGF}_{2} \alpha$ in human subjects was carried out in an attempt to study this.

\section{Materials and Methods}

Seven healthy volunteers aged 19-30 participated in this trial. Blood samples were collected daily or as often as possible throughout the menstrual cycle until the day of infusion. At identical times each morning $10-20 \mathrm{ml}$ of blood was collected into a plastic syringe, transferred to heparinized tubes, and centrifuged. The plasma was separated and deep frozen at $-20^{\circ} \mathrm{C}$ until analysed. Samples were taken before and during the $\mathrm{PGF}_{2} \alpha$ administration at least every two hours. After the infusion daily sampling was continued until menstruation occurred. In two subjects hourly samples of blood were taken for seven hours on day 23 of a subsequent menstrual cycle without administration of pharmacological compounds.

Prostaglandin $\mathrm{F}_{2} \propto$ (tromethamine salt) was diluted in $500 \mathrm{ml}$ of isotonic saline and infused by means of an IVAC 501 automatic drip pump (Tekmar Ltd., London). The dose administered was increased at half- to one-hourly intervals until side effects of vomiting, nausea, and uterine cramps appeared. The dose was then reduced to give the maximum tolerated dose with minimal side effects.

The duration and dosage of the infusion is shown in the Table.

Plasma progesterone was measured by competitive protein binding using the method of Johansson (1969). Total immunoreactive oestrogens were assayed without any chromatographic separation (Abraham, Odell, Edwards, and Purdy, 1970) using and antibody selective for oestradiol (kindly donated by $\mathrm{Dr}$. Exley). Oestradiol was measured after thin-layer chromatography by competitive protein binding (Corker, Exley, and Naftolin, 1970).

\section{Results}

The dose, duration of infusion, cycle details, and side effects for each of the infused subjects are shown in the Table. The side effects were not so severe to warrant curtailing the infusion but the administered dose was reduced when symptoms of vomiting and uterine cramps became obvious.

Individual hormonal levels indicated that three subjects (Cases 5, 6, and 7) were in the early luteal phase of their menstrual cycles, whereas the levels in Cases 1 to 4 conformed with the infusion being administered in the mid-late luteal phase.

The hormonal pattern of one subject infused during the early luteal phase is shown in Fig. 1. Progesterone levels continued to rise during the infusion; LH and oestrogen levels were unaffected.

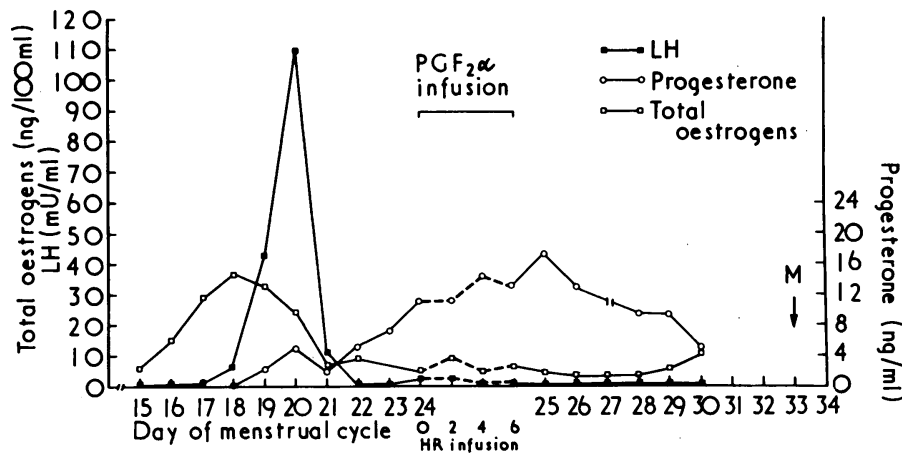

FIG. 1-Case 6. Plasma progesterone, total oestrogen, and LH levels during menstrual cycle. Levels during infusion of $\mathrm{PGF}_{2} \alpha$ in early luteal phase are shown on expanded hourly scale indicated by broken line. $M .=$ Onset of menstruation.

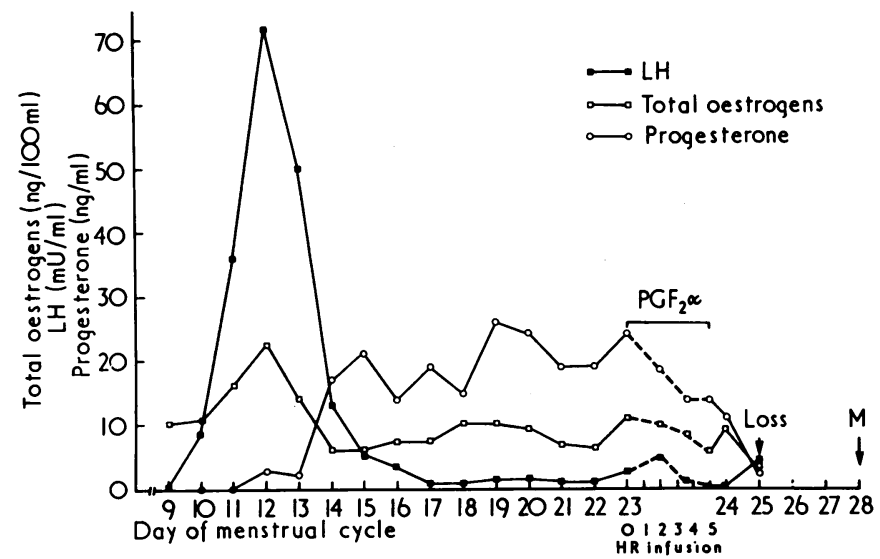

FIG. 2-Case 3. Plasma progesterone, total oestrogen, and LH levels during menstrual cycle. Levels during infusion of $\mathrm{PGF}_{2} \alpha$ in late luteal phase are shown on expanded hourly scale by broken line. Intermenstrual vaginal loss and menstruation are indicated by arrows. M.= Onset of menstruation.

On the day after the infusion levels of progesterone increased further before declining. The luteal phase lasted 13 days with menstruation occurring nine days after the infusion.

The effect of $\mathrm{PGF}_{2} \alpha$ in the late luteal phase, 11 days after ovulation, is shown in Fig. 2. During the infusion progesterone levels fell markedly and total plasma oestrogens declined slightly. A slight rise in LH levels occurred before falling during the latter part of the infusion. Vaginal spotting occurred two days

Intravenous Infusion of Prostaglandin $F_{2} \alpha$ in the Luteal Phase of the Menstrual Cycle

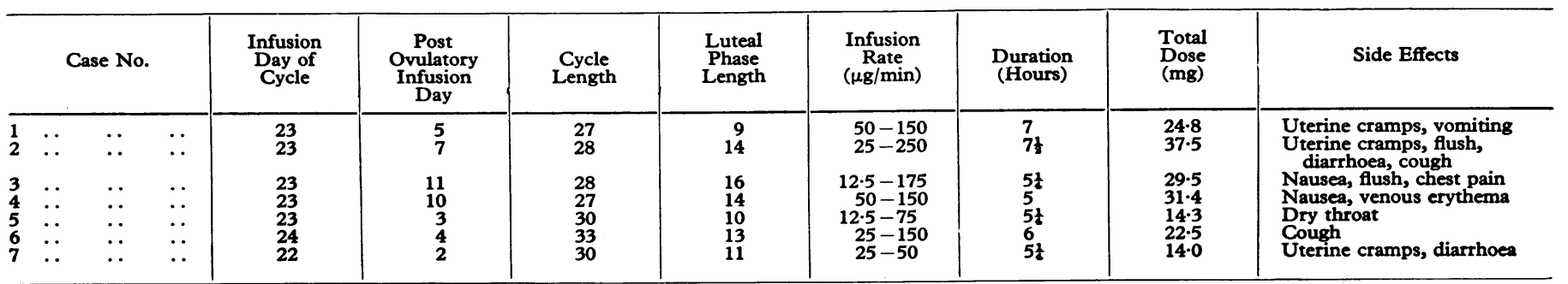




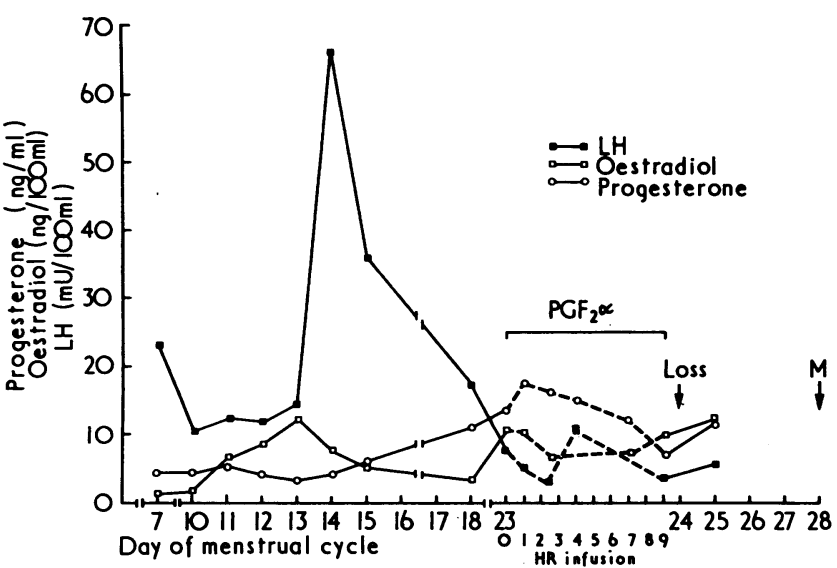

FIG. 3-Case 2. Plasma progesterone, oestradiol, and LH levels during menstrual cycle. Levels during infusion of $\mathrm{PGF}_{2} \alpha$ are shown on expanded hourly scale by broken lines. Intermenstrual vaginal loss and menstruation are shown by arrows. $\mathbf{M}$. = Onset of menstruation. Note rise in plasms progesterone above preinfusion levels during infusion.

after the infusion, and menstruation ensued three days after this loss.

The hormonal pattern in a subject infused in the mid-luteal phase (Case 2) is shown in Fig. 3. An initial rise in progesterone was followed by an appreciable decline to below preinfusion levels. 17 $\beta$-Oestradiol levels also fell during the first four hours of the infusion but rose towards the end, while LH levels rose and then fell during the infusion.

In the days after the infusion plasma progesterone $17 \beta-$ oestradiol, and LH levels increased above the values observed at the end of the infusion period. Fairly heavy vaginal spotting started on the day after the infusion and persisted until menstruation started on the 28 th day of the cycle.

The fall in progesterone levels during the infusion period and the measured levels subsequent to prostaglandin administration in the mid or latter part of the luteal phase are shown on an expanded scale in Fig. 4. Apart from Case 2 no rise in progesterone levels above preinfusion values occurred during or subsequent to the intravenous administration.

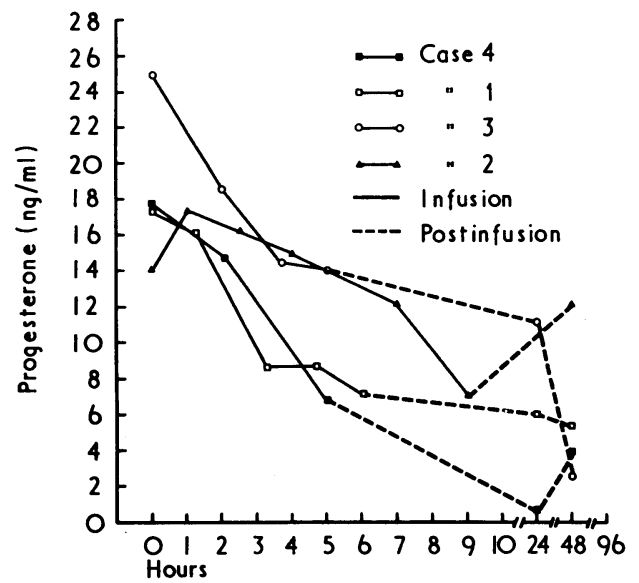

FG. 4-Plasma progesterone levels before and during infusion of prostaglandin $F_{2} \alpha$ in Cases $1,2,3$, and 4 in mid-late luteal phase of menstrual cycle.

The progesterone levels of the three subjects (Cases 5, 6, and 7) treated during the earlier part of the luteal phase are shown in Fig. 5. During the infusion period, two of the three exhibited a slight increase in progesterone levels above preinfusion values, and this was maintained for at least 24 hours after treatment.

In two subjects previously infused with $\mathrm{PGF}_{2} \alpha$, blood samples were taken at frequent intervals on day 23 of a subsequent cycle without administration of $\mathrm{PGF}_{2} \alpha$. The plasma progesterone levels in Case 3 (Fig. 6) showed a pronounced variability during the seven-hour sampling period. Oestrogen levels were less variable and little cyclic changes were seen. In the second sub-

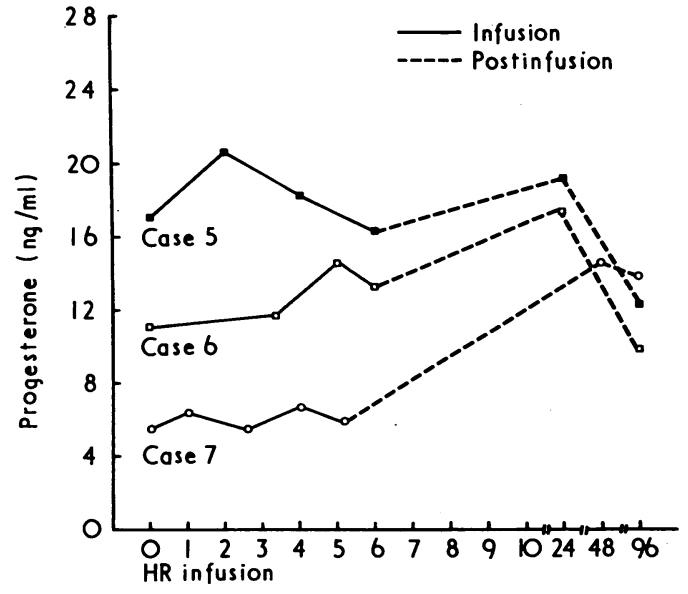

FIG. 5-Plasma progesterone levels before and during infusion of prostaglandin $F_{\gamma} \alpha$ in Cases 5,6 , and 7 in early luteal phase of menstrual cycle.

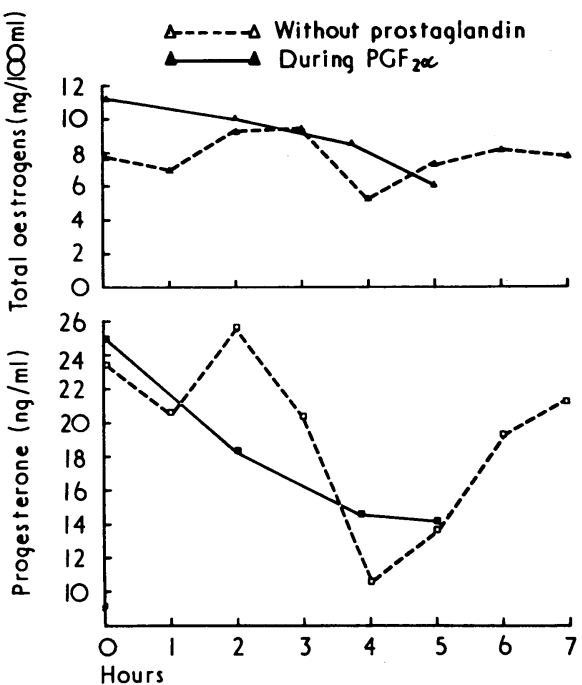

FIG. 6-Case 3. Variation in peripheral plasma progesterone and total oestrogen levels on day 23 of control menstrual cycle without infusion of prostaglandin compared with plasma levels on day 23 of a cycle in same subject during infusion of PGF

ject no significant diurnal variation was seen in progesterone or oestrogens.

The luteal phase length was not reduced in any volunteer receiving $\mathrm{PGF}_{2} \alpha$. Three in the mid-late luteal phase (Cases 1 , 2,3 ) and one in the early luteal phase (Case 5) experienced vaginal spotting during or after the infusion and in two (Cases 1 and 2) on whom histological examination of the loss was carried out, vaginal squames but no endometrial debris were reported. In all subjects the menstrual flow was of normal duration. Two described the flow as more heavy than usual; these had both shown a fall in progesterone during the infusion, and premenstrual spotting in one (Case 2) was particularly heavy.

All subjects subsequently had normal menstrual periods.

\section{Discussion}

In this study a sharp fall in plasma progesterone occurred in four volunteers infused with $\mathrm{PGF}_{2} \alpha$ at a time when a natural decline in the levels might be expected. In marked contrast, the progesterone levels of subjects in the early luteal phase were not affected by the infusion. In three of the subjects in the late luteal phase the decreased levels were maintained as long as the infusion was continued, with no cyclic variability, whereas one subject (Case 2) showed a rise preceding the decline in plasma concentrations.

It is thought unlikely that the observed fall in plasma progesterone was due to diurnal fluctuation. A contribution to the decline, however, may have been made by physiological varia- 
bility, as noticeable deviation in progesterone levels was shown in one control cycle (Fig. 6), although in another case studied little change was noted.

The fall in levels during the infusion was more precipitous than that observed during untreated menstrual cycles. After the infusion in the late luteal phase levels continued to fall in three of the four volunteers, whereas in the subjects in the early luteal phase progesterone levels rose subsequent to the infusion. LeMaire and Shapiro (1972) found little cyclic variation in progesterone levels in patients infused with saline in the luteal phase, whereas Henzl et al. (1972) showed pronounced spontaneous fluctuation.

In the present study, despite the decrease in progesterone levels, the luteal phase of the menstrual cycle was not reduced. While the work reported in this paper was in progress, LeMaire and Shapiro (1972) published a similar study of five volunteers using low doses of $\mathrm{PGF}_{2} \alpha(25-46 \mu \mathrm{g} / \mathrm{min})$ infused in the early luteal phase and one infused in the late luteal phase; prostaglandins had no effect. In the fifth subject, also in the late luteal phase, infused when progesterone levels were already declining, a drop in progesterone was noted; the luteal phase length was not reduced.

Prostaglandin $F_{2} \alpha$ was infused intravenously during the early luteal phase in six non-pregnant women (Wiqvist et al., 1970). Four subjects were infused with 9-12 $\mu \mathrm{g} / \mathrm{min}$ and two with 50-100 $\mu \mathrm{g} / \mathrm{min}$ for a period of eight hours a day on two successive days. A slight transient decrease in plasma progesterone occurred. The luteal phase length was not reduced.

Henzl et al. (1972) noted no shortening of the luteal phase or fall in plasma progesterone beyond normal variability in seven volunteers infused with $\mathrm{PGE}_{2}$. They did not find intermenstrual bleeding in any volunteer infused with $\mathrm{PGE}_{\text {, }}$ unlike the present series where four subjects experienced premenstrual loss. The disparity could be due to differences in prostaglandins used and the severity of uterine contractions.

This study indicates that systemically-administered prostaglandin $F_{2} \alpha$ is unsuitable for depressing the progesterone synthesizing capability of the human corpus luteum. High doses are required before progesterone levels are affected; and this is associated with side effects similar to those seen during $\mathrm{PGF}_{2} \alpha$ infusion in early pregnancy (Hillier and Embrey, 1972).

The naturally occurring prostaglandins are local hormones, and it is possible that the tissue level achieved at the site of action-for example, in the corpus luteum or pituitary-may be critical. However, if high systemic levels are required to produce such tissue concentrations then concomitant adverse side effects will occur. It is possible that more prolonged application of a low dosage of $\mathrm{PGF}_{2} \alpha$-for example, via a vaginal pessary-may be more acceptable, but this is unlikely to be adequately effective considering the rapid inactivation of it in the lungs and liver.

There are pronounced species differences in the luteolytic capacity of systemically-applied $\mathrm{PGF}_{2} \alpha$. It seems likely that it is potently luteolytic only where a uterine component for regression exists.

It is likely that an effect will be seen only over a limited period of time in the luteal phase, possibly where relative levels of other factors allow an optimum response.

A long-acting prostaglandin analogue with high luteolytic activity but low smooth muscle stimulating activity in the primate will be of interest to investigators in this field.

We are extremely grateful to the volunteers without whom this study would not have been possible. We thank Mr. John Bonnar, consultant gynaecologist, for useful comments on the manuscript, and Dr. Rex Jacomb, of the Upjohn Company Ltd., for supplies of prostaglandins.

This work has been supported by the Agency for International Development Contract No. AID/csd 2837 (granted to K.H. and M.P.E.).

\section{References}

Abraham, G. E., Odell, W. D., Edwards, R., and Purdy, J. M. (1970). Acta Endocrinologica (Kobenhavn), Suppl. No. 147, p. 332.

Blatchley, F. R., and Donovan, B. T. (1969). Nature, 221, 1065.

Corker, C. S., Exley, D., and Naftolin, F. (1970). In Karolinska Symposium on Research Methods in Reproductive Endocrinology, ed. E. Diczfalusy. p. 305. Copenhagen, Bogtrykkeriet Forum.

Henzl, M. R., Ortega, E., Cortes-Gallegos, V., Tomlinson, R. V., and Segre, E. J. (1972). In press.

Hillier, K., and Embrey, M. P. (1972). Fournal of Obstetrics and Gynaecology of the British Commonwealth, 79, 14.

Johansson, E. D. B. (1969). Acta Endocrinologica (Kobenhavn), 61, 592.

Karim, S. M. M. (1971). Contraception, 3, 173.

Kirton, K. T. (1972). In Prostaglandins in Fertility Control, vol. 2. Stockholm, W.H.O. Research and Training Centre on Human Reproduction.

Kirton, K. T., Pharriss, B. B., and Forbes, A. D. (1970). Proceedings of the Society for Experimental Biology and Medicine, 133, 314.

Lehmann, F., Peters, F., Breckwoldt, M., and Bettendorf, G. (1972). Prostaglandins, 1,269.

LeMaire, W. J., and Shapiro, A. G. (1972). Prostaglandins, 1, 259.

McCracken, J. A., Glew, M. E., and Scaramuzzi, R. J. (1970). Fournal of Clinical Endocrinology and Metabolism, 30, 544.

Midgley, A. R. (1966). Endocrinology, 79, 10.

Pharriss, B. B., and Wyngarden, L. J. (1969). Proceedings of the Society for Experimental Biology and Medicine, 130, 92.

Wiqvist, N., Bygdeman, M., and Kirton, K. T. (1970). In Nobel Symposium, ed. E. Diczfalusy and V. Borell, vol. 15, p. 137. New York, John Wiley.

\title{
Comparison between Urinary Oestrogen Assay and Serial Ultrasonic Cephalometry in Assessment of Fetal Growth Retardation
}

\author{
STUART CAMPBELL, ASIM KURJAK
}

British Medical fournal, 1972, 4, 336-340

\section{Summary}

Urinary oestrogen assay and serial ultrasonic cephalometry were performed on 284 patients who were considered on clinical grounds to be at risk of having a

Institute of Obstetrics and Gynaecology, Queen Charlotte's Maternity Hospital, London W.6

STUART CAMPBELL, M.B., M.R.C.O.G., Senior Lecturer ASIM KURJAK, M.D., British Council Scholar growth-retarded fetus. It was found that ultrasonic cephalometry was significantly better than oestrogens in diagnosing the small-for-dates baby, but that there was no significant difierence between the two methods in predicting perinatal asphyxia. Of the 14 stillbirths, three were in the normal ultrasonic growth rate group and five had normal oestrogen excretion. Both methods were found to be of value in the diagnosis of fetal growthretardation, although cephalometry would seem to have some advantages, especially in distinguishing between fetal growth-retardation and mistaken maturity. 